Preventive Care in Nursing and Midwifery Journal

2020; 10(2): 9-18

\title{
Determination of Recurrence, Severity, Distress, and Clustering of Symptoms in the Elderly with Colorectal Cancer in Selected Hospitals in Isfahan - Iran in 2018 to 2019
}

\author{
Esmaeili $\mathrm{A}^{1} \mathbb{\oplus}$, Khorasani $\mathrm{P}^{2} \mathbb{D}$, Bahrami $\mathrm{M}^{3} \mathbb{D}, \underline{\text { Hosseini }}^{4^{*}}{ }^{\mathbb{1 0}}$ \\ ${ }^{1}$ MSc Student, faculty of Nursing and Midwifery, Isfahan University of Medical Sciences, Isfahan, Iran \\ ${ }^{2} \mathrm{PhD}$ in nursing, Nursing and Midwifery Care Research Center, Department of Community Health Gerontological Nursing, School of Nursing \\ and Midwifery, Isfahan University of Medical Sciences, Isfahan, Iran \\ ${ }^{3} \mathrm{PhD}$ in nursing, Professor of Nursing, Nursing and Midwifery Care Research Center, School of Nursing and Midwifery, Isfahan University of \\ Medical Sciences, Isfahan, Iran \\ ${ }^{* 4}$ Master in nursing, Nursing and Midwifery Care Research Center, Health Department, Faculty of Nursing and Midwifery, Isfahan University \\ of Medical Sciences, Isfahan, Iran
}

“Corresponding Author: Master in Nursing, Nursing and Midwifery Care Research Center, Health Department, Faculty of Nursing and Midwifery, Isfahan University of Medical Sciences, Isfahan, Iran

Tel: 0098-9132703518

Email: h_hoseini@nm.mui.ac.ir

Received: 3 Oct $2020 \quad$ Accepted: 4 Nov 2020

\begin{abstract}
Background: Colorectal cancer (CRC) is one of the most common and age-related cancers worldwide.

Objectives: The present study aimed to determine the recurrence, severity, distress, and clustering of symptoms in the elderly with colorectal cancer in the selected hospitals in Isfahan from 2018 to 2019.

Methods: This descriptive-analytical study was conducted over a period of six months on 300 patients with colorectal cancer in selected hospitals in Isfahan. Data collection tools were contextual questionnaires and symptom recall scale (MSAS). To determine the correlation matrix between symptoms (clusters), a heuristic analysis factor was used in terms of mean recurrence, severity, and distress of symptoms in research units through PCA heuristic analytical method in SPSS 16.

Results: The most common symptoms in terms of recurrence were dry mouth (32.92\%) and numbness and frisson $(24.55 \%)$. The most common symptoms in terms of recurrence were dry mouth $(80.33 \%)$ and nausea (86\%); the most common symptoms in terms of severity were dry mouth (41\%) and nausea (29.8\%). The most common signs of distress were "I do not look like myself" (6) and dry mouth (35.3\%). Finally, five clusters were obtained, including systemic, psychiatric, cardiovascular, mucosal, and gastrointestinal symptoms.

Conclusion: The results of the present study showed that psychological symptoms had a higher percentage of recurrence, severity, and distress in CRC patients than physical symptoms.
\end{abstract}

\section{Keywords: Cluster symptoms, the elderly, colorectal cancer}

\section{Introduction}

Cancer is one of the world's deadliest factors after cardiovascular diseases [1,2]. Approximately 8.8 million people are exposed to cancer each year, accounting for one in six deaths worldwide $[3,4]$. Colorectal cancer (CRC) is one of the most lethal cancers in the world. In 2017, with 1.4 new cases, CRC accounted for $9.9 \%$ of all global cancers [5]. The highest incidence of colorectal cancer in Iran was related to the provinces of Tehran (16.78), East Azerbaijan (14.41), Semnan (13.62). Isfahan province is in fifth place. The incidence rate is (13.29) in men and (12.18) in women [6]. CRC, which increases with age, has several distressing symptoms, such as pain, fatigue, vomiting, weight loss, bleeding, and the deterioration in quality of life [7]. 
Today, one of the strategies that can help prolong the life of cancer patients and control its complications is to assess the status of the symptoms of the disease [8]. Symptom management means providing care to improve the quality of life of patients with a serious and lifethreatening illness. It aims to prevent or promptly treat the symptoms, the side effects of treatment, psychological, social, and spiritual problems associated with the disease or treatment [9]. Therefore, a symptom or a set of symptoms of a disease can be managed when they are examined from different aspects, such as recurrence, severity, and distress $[8,10]$.

Given the importance of CRC and its prevalence among the elderly and despite the importance of clustering symptoms in cancers and its application in improving the quality of nursing care, clustering symptoms in addition to developing diagnostic criteria for the disease and identifying potential disease mechanisms with unknown cause plays an important role in predicting clinical outcomes such as quality of life-related to health, functional status and ultimately symptom management [11]. Therefore, the present study aimed to determine the recurrence, severity, distress, and clustering symptoms among the elderly with CRC in the selected hospitals of Isfahan from 2018 to 2019.

\section{Methods}

The present descriptive and analytical study was conducted in the form of a master's thesis approved by the ethics committee of Isfahan University of Medical Sciences (ethics code: ir.Mui.Reserch.Rec.1397.371). The statistical population was the elderly with non-metastatic colorectal cancer treated in selected hospitals in Isfahan (Omid and Milad) who met the inclusion requirements.

Inclusion criteria were the elderly over 60 years of age with non-metastatic colorectal cancer listed on the patient record or undergoing treatment with one of the chemotherapy, surgery, or radiation treatments. The exclusion criterion was the participants' incomplete completion of the questionnaire.

The sample size in this study is via the formula for determining the mean with $95 \%$ confidence level and $80 \%$ test power, 240 samples and finally with $20 \%$ loss of 300 elderly people, which were selected in the form of quota from Isfahan's two reference cancer hospitals, called Omid (240 elderly) and Milad (60 elderly) where CRC patients underwent surgery, chemotherapy, and radiotherapy.

Data collection tools via background information questionnaire included age, sex, marriage, number of children, education, occupation, income, residence, lifestyle, type of disease, severity of disease, duration of diagnosis, type of treatment, duration of hospitalization, the history and degree of the disease, and the questionnaire of the "Memorial Symptom Assessment Scale." The validity and reliability of this questionnaire was confirmed by Partini et al. (1994) by evaluating the randomly selected patients with prostate, colon, breast, and ovarian cancers [12]. In this questionnaire, the Memorial Symptom Assessment Scale included 32 common symptoms in two parts. To examine the first part with 24 symptoms, we selected the three aspects of recurrence or recurrence, distress, and severity. These symptoms include difficulty concentrating, pain, lack of energy, cough, nervousness, dry mouth, nausea, lethargy, numbness and frisson in the hands, sleep disturbance, bloating, difficulty urinating, vomiting, shortness of breath, diarrhea, feelings of sadness, sweating, anxiety, sexual dysfunction, pruritus, loss of appetite, dizziness, difficulty swallowing, and irritability. The second part of the questionnaire has eight symptoms evaluated only in terms of severity and distress. These symptoms include inflammation or sores in the mouth, changes in taste, weight loss, hair loss, constipation, swelling of the hands, skin changes, and the phrase "I do not look like myself." The scoring of this questionnaire was based on the Likert scale. Thus, the scores of the first 24 symptoms, which were measured in terms of the three aspects of recurrence rate, severity, and distress, were as follows: "Distress" at all to a very high score of 1 to 4 .

For sampling based on the statistics of patients in the last 6 months in two hospitals, quotas were imposed. Then, easy sampling was performed on the patients admitted to the wards. By referring to the patients' files, the degree of the disease was determined through pathology (If the degree of the disease was not known, it would be determined from the documents of the patients or in the archive). In order to complete the 
questionnaires from 2018.10.23 to 2019.6.20, we went to Milad Hospital on even days and Omid Hospital on odd days (between 8 and 12 o'clock). Having considered the patients' condition at their bedside and convinced them, we provided the necessary explanations, so they would sign the informed consent. After that, we completed the background characteristics and the symptom recall scale in a face-to-face manner and in the form of a questionnaire. A colleague (who had previously been provided with the necessary training) was also used to complete the questionnaire at Milad Hospital. Data were collected from 300 samples of colorectal cancer patients after chemotherapy, surgery, and radiotherapy in Milad and Omid hospitals, and the data were analyzed after coding in SPSS software version. 6 To analyze the data of the present study, central and dispersion indices were used for descriptive statistics. To determine the correlation matrix between symptoms (clusters), a heuristic analysis factor was used in terms of mean recurrence, severity, and distress of symptoms in research units through PCA heuristic analytical method in SPSS software version 16. For this purpose, first, the quality of the data was measured to perform the exploratory analysis factor. Then, the varimax rotation method was used to determine how the questionnaire items were grouped.

\section{Results}

The results of the demographic information frequency from a total of 300 patients with colorectal cancer showed that the type of disease among $58.39 \%$ of male patients, patients between 60-69 years of age with $230(78.23 \%) 230$, (94.98\%) 284 married patients, (37 111\% with three children, $(67.32 \%) 98$ undergraduate students, (38\%) 93 retirees or housewives, (49.73\%) 219 middle-income people, (90.78\%) 266 urban dwellers, (69.90\%) 29 people who lived with their spouses, has been equal to (76.85\%) 229 colon cancers. For a number 151 $(0.67 \%)$ of patients, the diagnosis time is between 6 to 12 months. Also, the type of treatment for patients who have been treated with chemotherapy is equal to $(68.33 \%)$. Also, the length of hospital stay between 3 to 5 days is equal to $(39.46 \%) 118$, and for people who have no history of other diseases, it has been equal to $(49.83 \%)$. In the present study, out of 32 symptoms of the disease, 10 had more frequent symptoms than other symptoms, including dry mouth, lack of energy, nausea, feeling dull, numbness and murmurs of the hands, sleep disturbance, bloating, anxiety, sadness, and loss of appetite (Table 1). 
Table 1: Prevalence of recurrence, severity, and distress in patients with colorectal cancer in the studied units

\begin{tabular}{|c|c|c|c|c|c|c|c|c|c|}
\hline Symptom & $\begin{array}{c}\text { Percent } \\
\text { Outbreak }\end{array}$ & $\begin{array}{c}\text { Percent } \\
\text { recurrence }\end{array}$ & $\begin{array}{l}\text { Percent } \\
\text { severity }\end{array}$ & $\begin{array}{l}\text { Percent } \\
\text { distress }\end{array}$ & Symptom & $\begin{array}{l}\begin{array}{l}\text { Percent } \\
\text { outbreak }\end{array} \\
\end{array}$ & $\begin{array}{c}\text { Percent } \\
\text { recurrence }\end{array}$ & $\begin{array}{l}\text { Percent } \\
\text { severity }\end{array}$ & $\begin{array}{l}\text { Percent } \\
\text { distress }\end{array}$ \\
\hline $\begin{array}{l}\text { Feeling } \\
\text { bloated }\end{array}$ & 73.67 & 44.55 & 34 & 33.7 & $\begin{array}{c}\text { Difficulty } \\
\text { concentrating }\end{array}$ & 59.33 & 69.66 & 42.7 & 36 \\
\hline $\begin{array}{l}\text { Difficulty } \\
\text { urinating }\end{array}$ & 24.67 & 45.95 & 9.3 & 11.7 & the pain & 69 & 41.55 & 31 & 29 \\
\hline $\begin{array}{c}\text { Sexual } \\
\text { dysfunction }\end{array}$ & 65.89 & 36.73 & 23.7 & 18.7 & $\begin{array}{l}\text { Lack of } \\
\text { energy }\end{array}$ & 86.33 & 54.83 & 49 & 47.3 \\
\hline Itching & 49 & 34.93 & 18 & 20 & Cough & 36.24 & 38.89 & 16 & 16.3 \\
\hline $\begin{array}{c}\text { Decreased } \\
\text { appetite }\end{array}$ & 88.67 & 37.97 & 34 & 36.7 & $\begin{array}{l}\text { Feeling } \\
\text { nervous }\end{array}$ & 58.72 & 64.57 & 36.7 & 36 \\
\hline Vertigo & 61.33 & 44.02 & 27.3 & 30.7 & Dry mouth & 80.33 & 32.92 & 26.7 & 35.3 \\
\hline Dysphagia & 53.33 & 35 & 22 & 21 & Vomit & 57 & 49.12 & 26.3 & 26.7 \\
\hline $\begin{array}{l}\text { Feeling } \\
\text { irritable }\end{array}$ & 39.80 & 53.78 & 24 & 24.3 & $\begin{array}{c}\text { Shortness of } \\
\text { breath and } \\
\text { shortness of } \\
\text { breath }\end{array}$ & 30.67 & 54.35 & 17.3 & 18.7 \\
\hline Oral ulcers & 47.14 & - & 26.7 & 25.7 & Diarrhea & 52 & 50 & 24 & 23.3 \\
\hline Taste change & 37.71 & - & 21.7 & 20.7 & Feeling sad & 82 & 63.01 & 50.7 & 52 \\
\hline Weight Loss & 56.90 & - & 27.7 & 29 & Sweating & 42 & 51.59 & 21.7 & 21.7 \\
\hline hair loss & 58.11 & - & 28.7 & 29.7 & worry & 82 & 57.96 & 45.3 & 46.7 \\
\hline Constipation & 29.73 & - & 15.7 & 17 & Nausea & 86 & 41.86 & 27.3 & 36.7 \\
\hline $\begin{array}{l}\text { Swelling in } \\
\text { the hands }\end{array}$ & 21.96 & - & 9 & 9.7 & Feeling bored & 77.33 & 57.76 & 45 & 42.3 \\
\hline $\begin{array}{l}\text { I don't look } \\
\text { like myself }\end{array}$ & 26.01 & - & 5.3 & 6 & $\begin{array}{l}\text { Anesthesia } \\
\text { and hand } \\
\text { frisson }\end{array}$ & 74.67 & 24.55 & 19.3 & 18.3 \\
\hline Skin changes & 39.53 & - & 21 & 21 & $\begin{array}{c}\text { Sleep } \\
\text { disorder }\end{array}$ & 82.94 & 37.50 & 35 & 33 \\
\hline
\end{tabular}

Also, in the frequency distribution of symptom severity in the studied units, out of a total of 300 research units, 239 patients experienced the symptoms of "dry mouth," and the highest response to the item "severe" was $41 \%$. A total of 258 patients experienced symptoms of "nausea," and the highest response to the item "severe" was reported with $29.8 \%$. A total of 246 patients experienced symptoms of "numbness and frisson", with the highest response being "severe" at $29.3 \%$.
Moreover, the prevalence of distress symptoms in 300 hospitalized research units indicated that 77 patients experienced the "I do not look like myself" symptom, with the highest response being reported as "too much" with 7.7\%, 238 patients. They experienced "dry mouth" and the highest response to the item "high" was reported with $35.3 \%$.

Also, the results of the factor analysis of symptoms included five clusters, including: gastrointestinal, systemic, psycho-psychological, cutaneous-mucosal, and cardiovascular (Table 2). 
Table 2: Factor analysis of symptoms in patients with colorectal cancer in the studied units

\begin{tabular}{|c|c|c|c|c|}
\hline Factor & Symptoms & $\begin{array}{c}\text { Load } \\
\text { Factor }\end{array}$ & $\begin{array}{c}\text { Percentage of } \\
\text { explained } \\
\text { variance }\end{array}$ & eigenvalues \\
\hline \multirow{6}{*}{$\begin{array}{l}\text { gastrointestinal } \\
\mathbf{7 , 1 1 , 2 3 , 2 5 , 2 6 , 2 9}\end{array}$} & Nausea & 0.75 & \multirow{6}{*}{10.54} & \multirow{6}{*}{2.28} \\
\hline & Blowing & 0.83 & & \\
\hline & Difficulty swallowing & 0.70 & & \\
\hline & Oral ulcers & 0.82 & & \\
\hline & $\begin{array}{l}\text { Change in the taste of } \\
\text { food }\end{array}$ & 0.75 & & \\
\hline & Constipation & 0.80 & & \\
\hline \multirow{8}{*}{$\begin{array}{c}\text { Systemic } \\
\mathbf{2 , 3 , 8 , 9 , 1 7 , 1 9 , 2 1 , 2 7}\end{array}$} & the pain & 0.43 & \multirow{8}{*}{8.70} & \multirow{8}{*}{1.89} \\
\hline & Lack of energy & 0.63 & & \\
\hline & To be bored & 0.65 & & \\
\hline & $\begin{array}{l}\text { Anesthesia and hand } \\
\text { murmurs }\end{array}$ & 0.70 & & \\
\hline & Sexual dysfunction & 0.62 & & \\
\hline & Lack of appetite & 0.51 & & \\
\hline & Sweating & 0.41 & & \\
\hline & Weight Loss & 0.62 & & \\
\hline Factor & Symptoms & $\begin{array}{l}\text { Load } \\
\text { Factor }\end{array}$ & $\begin{array}{c}\text { Percentage of } \\
\text { explained } \\
\text { variance }\end{array}$ & eigenvalues \\
\hline \multirow{7}{*}{$\begin{array}{c}\text { Mental } \\
\mathbf{1 , 5 , 1 0 , 1 6 , 1 8 , 2 4 , 3 1}\end{array}$} & Impaired concentration & 0.45 & \multirow{7}{*}{18.82} & \multirow{7}{*}{11.48} \\
\hline & Being nervous & 0.47 & & \\
\hline & Sleep disorder & 0.39 & & \\
\hline & Feeling sad & 0.49 & & \\
\hline & worry & 0.67 & & \\
\hline & Feeling irritable & 0.63 & & \\
\hline & I don't look like myself & 0.44 & & \\
\hline \multirow{5}{*}{$\begin{array}{l}\text { Cardiovascular } \\
\text { and respiratory } \\
\mathbf{4 , 1 2 , 1 4 , 2 2 , 3 0}\end{array}$} & Cough & 0.57 & \multirow{5}{*}{7.35} & \multirow{5}{*}{1.77} \\
\hline & Difficulty urinating & 0.66 & & \\
\hline & $\begin{array}{l}\text { Shortness of breath and } \\
\text { shortness of breath }\end{array}$ & 0.65 & & \\
\hline & Vertigo & 0.48 & & \\
\hline & Hand and leg swelling & 0.77 & & \\
\hline \multirow{6}{*}{$\begin{array}{c}\text { Mucosal-dermal } \\
\mathbf{6 , 1 3 , 1 5 , 2 0 , 2 8 , 3 2}\end{array}$} & Dry mouth & 0.58 & \multirow{6}{*}{5.84} & \multirow{6}{*}{1.65} \\
\hline & Vomit & 0.62 & & \\
\hline & Diarrhea & 0.51 & & \\
\hline & Itching & 0.49 & & \\
\hline & hair loss & 0.63 & & \\
\hline & Skin changes & 0.61 & & \\
\hline
\end{tabular}

\section{Discussion}

The results of data analysis in the present study showed the average score in terms of (recurrence, severity, and distress) lack of energy, dullness, irritability, difficulty concentrating, I don't look like myself, weight loss and numbness and frisson in patients in the age group of 60-69 years were more than other age groups. However, the most severe weight loss and numbness and frisson were experienced in the age group of 70-79 years (Tables 3-5). 
Table 3: Comparison of the mean score of the recurrence of symptoms by age group in research units

\begin{tabular}{|c|c|c|c|c|c|c|}
\hline symptom & Age rate & number & average & $\begin{array}{l}\text { Standard } \\
\text { deviation }\end{array}$ & results & test \\
\hline \multirow{3}{*}{$\begin{array}{l}\text { Lack of } \\
\text { energy }\end{array}$} & $60-69$ & 199 & 2.54 & 0.802 & \multirow{3}{*}{$\begin{array}{c}\mathrm{P}=0.001 \\
\mathrm{df}=2 \\
\mathrm{f}=7.565\end{array}$} & \multirow{3}{*}{ ANOVA } \\
\hline & $70-79$ & 53 & 2.08 & 0.67 & & \\
\hline & $80-89$ & 4 & 2.25 & 0.5 & & \\
\hline \multirow{3}{*}{ Being bored } & $60-69$ & 187 & 2.40 & 0.79 & \multirow{3}{*}{$\begin{array}{c}\mathrm{P}=0.014 \\
\mathrm{df}=2 \\
\mathrm{f}=2.796\end{array}$} & \multirow{3}{*}{ ANOVA } \\
\hline & 70-79 & 42 & 2.12 & 0.702 & & \\
\hline & $80-89$ & 2 & 1.50 & 0.707 & & \\
\hline \multirow{3}{*}{ Irritability } & $60-69$ & 96 & 2.42 & 0.72 & \multirow{3}{*}{$\begin{array}{c}\mathrm{P}=0.006 \\
\mathrm{Df}=2 \\
\mathrm{~F}=5.428\end{array}$} & \multirow{3}{*}{ ANOVA } \\
\hline & 70-79 & 18 & 1.78 & 0.70 & & \\
\hline & $80-89$ & 2 & 2 & 0.71 & & \\
\hline \multirow{3}{*}{$\begin{array}{l}\text { Numbness } \\
\text { and frisson }\end{array}$} & $60-69$ & 181 & 2.40 & 0.877 & \multirow{3}{*}{$\begin{array}{c}\mathrm{P}=0.002 \\
\mathrm{df}=2 \\
\mathrm{f}=6.623\end{array}$} & \multirow{3}{*}{ ANOVA } \\
\hline & $70-79$ & 42 & 2.12 & 0.887 & & \\
\hline & $80-89$ & 4 & 1.50 & 0.707 & & \\
\hline
\end{tabular}

Table 4: Comparison of the mean score of the severity of symptoms by age groups in research units

\begin{tabular}{|c|c|c|c|c|c|c|}
\hline symptom & Age rate & number & average & $\begin{array}{l}\text { Standard } \\
\text { deviation }\end{array}$ & results & test \\
\hline \multirow{3}{*}{$\begin{array}{l}\text { Lack of } \\
\text { energy }\end{array}$} & $60-69$ & 199 & 2.52 & 0.78 & \multirow{3}{*}{$\begin{array}{c}\mathrm{P}=0.000 \\
\mathrm{df}=2 \\
\mathrm{f}=7.947\end{array}$} & \multirow{3}{*}{ ANOVA } \\
\hline & $70-79$ & 52 & 2.06 & 0.63 & & \\
\hline & $80-89$ & 4 & 2.25 & 0.5 & & \\
\hline \multirow{3}{*}{ Being bored } & $60-69$ & 181 & 2.40 & 0.84 & \multirow{3}{*}{$\begin{array}{c}\mathrm{P}=0.01 \\
\mathrm{df}=2 \\
\mathrm{f}=4.281\end{array}$} & \multirow{3}{*}{ ANOVA } \\
\hline & $70-79$ & 42 & 2.12 & 0.59 & & \\
\hline & 80-89 & 4 & 1.5 & 0.57 & & \\
\hline \multirow{3}{*}{ Weight Loss } & $60-69$ & 129 & 2.33 & 0.84 & \multirow{3}{*}{$\begin{array}{c}\mathrm{P}=0.001 \\
\mathrm{df}=2 \\
\mathrm{f}=7.64\end{array}$} & \multirow{3}{*}{ ANOVA } \\
\hline & $70-79$ & 34 & 2.52 & 0.77 & & \\
\hline & 80-89 & 3 & 1.94 & 0.57 & & \\
\hline \multirow{3}{*}{$\begin{array}{l}\text { I don't look } \\
\text { like myself }\end{array}$} & $60-69$ & 66 & 2.80 & 1.117 & \multirow{3}{*}{$\begin{array}{c}\mathrm{P}=0.002 \\
\mathrm{df}=1 \\
\mathrm{f}=10.23\end{array}$} & \multirow{3}{*}{ ANOVA } \\
\hline & $70-79$ & 9 & 1.67 & 0.50 & & \\
\hline & $80-89$ & 0 & 0 & 0 & & \\
\hline \multirow{3}{*}{$\begin{array}{l}\text { Numbness } \\
\text { and frisson }\end{array}$} & $60-69$ & 197 & 2.80 & 0.91 & \multirow{3}{*}{$\begin{array}{c}\mathrm{P}=0.003 \\
\mathrm{df}=2 \\
\mathrm{f}=6.118\end{array}$} & \multirow{3}{*}{ ANOVA } \\
\hline & $70-79$ & 43 & 3.29 & 0.86 & & \\
\hline & $80-89$ & 2 & 3 & 1.7 & & \\
\hline
\end{tabular}


Table 5: Comparison of the mean score of the degree of distress of symptoms by age groups in research units

\begin{tabular}{|c|c|c|c|c|c|c|}
\hline symptom & Agerate & number & average & $\begin{array}{l}\text { Standard } \\
\text { deviation }\end{array}$ & results & test \\
\hline \multirow{3}{*}{ Lack of energy } & $60-69$ & 198 & 2.46 & 0.771 & $\mathrm{P}=0.000$ & \multirow{3}{*}{ ANOVA } \\
\hline & $70-79$ & 52 & 1.96 & 0.685 & $\mathrm{df}=2$ & \\
\hline & $80-89$ & 4 & 2.25 & 0.5 & $\mathrm{f}=9.26$ & \\
\hline \multirow{3}{*}{$\begin{array}{c}\text { Difficulty } \\
\text { concentrating }\end{array}$} & $60-69$ & 146 & 1.99 & 0.649 & $\mathrm{P}=0.01$ & \multirow{3}{*}{ ANOVA } \\
\hline & $70-79$ & 24 & 1.58 & 0.654 & $\mathrm{df}=2$ & \\
\hline & $80-89$ & 2 & 1.5 & 0.707 & $\mathrm{f}=4.54$ & \\
\hline \multirow{3}{*}{$\begin{array}{l}\text { Numbness and } \\
\text { frisson }\end{array}$} & $60-69$ & 170 & 2.72 & 0.91 & $\mathrm{P}=0.001$ & \multirow{3}{*}{ ANOVA } \\
\hline & $70-79$ & 84 & 3.27 & 0.086 & $\mathrm{DF}=2$ & \\
\hline & $80-89$ & 3 & 3 & 1.73 & $\mathrm{~F}=6.777$ & \\
\hline \multirow{3}{*}{$\begin{array}{l}\text { Swelling of hands } \\
\text { and feet }\end{array}$} & $60-69$ & 52 & 2.33 & 1.09 & $\mathrm{P}=0.04$ & \multirow{3}{*}{ ANOVA } \\
\hline & $70-79$ & 11 & 1.64 & 0.5 & $\mathrm{DF}=1$ & \\
\hline & $80-89$ & 0 & 0 & 0 & $\mathrm{~F}=4.12$ & \\
\hline \multirow{3}{*}{$\begin{array}{c}\begin{array}{c}\text { I don't look like } \\
\text { myself }\end{array} \\
\end{array}$} & $60-69$ & 66 & 2.80 & 1.14 & $\mathrm{P}=0.004$ & \multirow{3}{*}{ ANOVA } \\
\hline & $70-79$ & 9 & 1.67 & 0.5 & $\mathrm{DF}=1$ & \\
\hline & $80-89$ & 0 & 0 & 0 & $\mathrm{~F}=8.63$ & \\
\hline \multirow{3}{*}{ Being bored } & $60-69$ & 181 & 2.33 & 0.84 & $\mathrm{P}=0.618$ & \multirow{3}{*}{ ANOVA } \\
\hline & $70-79$ & 41 & 2.07 & 0.60 & $\mathrm{df}=1$ & \\
\hline & $80-89$ & 4 & 1.5 & 0.57 & $\mathrm{f}=0.249$ & \\
\hline
\end{tabular}

Also, from the results of this study, we found that the age group of 60-69 years had more psychological symptoms in terms of recurrence, severity, and distress, causing more symptoms in this age group due to age, underlying diseases, and the degree of the disease.

Bahrami et al. (2017) in Isfahan showed that the age group over 70 had more physical symptoms in terms of recurrence, severity, and distress [13]. However, most psychological symptoms occurred in the age group of 18 to 30 years. The reason for the difference in this age range was the type of statistical population and age range.

The mean score in terms of the amount (recurrence, severity, and distress) of the symptoms of difficulty concentrating, feeling nervous, feeling sad, heartbroken and feeling dull, sweating, changes in taste, skin changes, and heartburn were higher in women than men. The results also showed that the recurrence, severity, and distress of physical and mental symptoms were higher in women than men, which can be attributed to gender characteristics that basically say women have a lower tolerance and less financial support than men.

According to Bahrami et al. in 1996, the recurrence, severity, and distress of mental symptoms are higher in women, which is in line with the present study. This can be attributed to gender characteristics saying that women are less tolerant than men [8].
According to the results of the data test, the mean score of recurrence, severity, and distress of symptoms with the number of children showed that patients with more than four children had more mental and physical symptoms than others, and they cared more for their family. Naseri et al. in Isfahan (1998) investigated the relationship between demographic variables and depression in cancer patients. Their results showed that there was an effective relationship between the number of children and depression in cancer patients. This relationship was confirmed in the previous studies in this field. These studies have also verified higher rates of depression in children with cancer than in children without cancer. Although some studies have suggested a lack of association between the number of children with depression, which may be related to their low sample size $[13,14]$, one study found that support from family members, especially children, played an important role in relieving symptoms of depression in cancer patients [15].

The results showed that patients who were diagnosed with cancer for less than 6 months had more psychological and physical symptoms in terms of recurrence, severity, and distress, probably because they were unable to adapt emotionally and did not accept the disease.

Naseri et al. observed no variables related to the disease (including the duration of the disease, type of treatment, and location of the disease) with 
depression and no statistically significant relationship [14]. Also, the studies by Caraboloteniz confirm that such a relationship does not exist [16]. Depression seems to increase in parallel during treatment because denial is one of the defense mechanisms used by cancer patients to reduce anxiety and worry, which is usually effective during the first year of diagnosis and treatment [17].

The present study showed that patients undergoing radiotherapy had recurrent problems with concentration, pain, lack of energy, cough, nervousness, nausea, drowsiness, sleep disturbance, bloating, difficulty urinating, vomiting. They had shortness of breath, diarrhea, sadness, sweating, anxiety, sexual dysfunction, pruritus, loss of appetite, dizziness, and difficulty swallowing. They also experienced more psychological and physical symptoms in terms of recurrence, severity, and distress than others who received other treatments.

Salehi et al. showed that the quality of life of patients has improved after the supportive and educational care of nurses in order to examine the effect of supportive and educational care of nurses on the quality of life of patients with breast cancer referred for radiotherapy [18]. A study by Fafouti $M$ in Athens (2010) showed that the rate of depression and anxiety in the patient group was significantly higher than the healthy group to examine the psychological factors such as depression and anxiety in women with breast cancer [19]. Pedram et al. rated the patients' the psychological side effects of treatment such as anger, anxiety or worry more severely than physical side effects such as hair loss and nausea. Some of these patients quit chemotherapy for problems and crises caused by the disease [20].

The limitations of the study include the need for training to answer the questionnaire questions correctly, which was checked by the researcher before completing the study, and the plight of most cancer patients, which may affect the completion of the questionnaire, lack of cooperation, lack of correct understanding, and lack of answers to all questions in some questionairs (To control these issues, the questionnaire was completed patiently and carefully at the appropriate time by questioning the sample).

\section{Conclusion}

The results of the present study showed that the most common symptoms in CRC patients include in terms of recurrence: dry mouth, numbness, and frisson and in terms of recurrence: dry mouth and nausea and in terms of distress: dry mouth. Also, by examining the most common symptoms, which have been experienced by more than $50 \%$ of the research units, we find that psychological symptoms have the highest percentage in terms of recurrence, severity, and distress in these patients . The present study showed that female patients had more psychological and physical symptoms than men. The longer is the duration of hospitalization of these patients, the greater will be the psychological and physical symptoms. Thus, it is necessary to design the treatment and support of these patients to reduce the duration of hospitalization of these patients. Also, more attention should be paid to psychological support and counseling and assistance for patients whose diagnosis is less than 6 months because psychological symptoms are more than physical symptoms in this group. In addition, patients receiving radiotherapy experienced more psychological and physical symptoms in terms of recurrence, severity, and distress than others who used other treatments. 


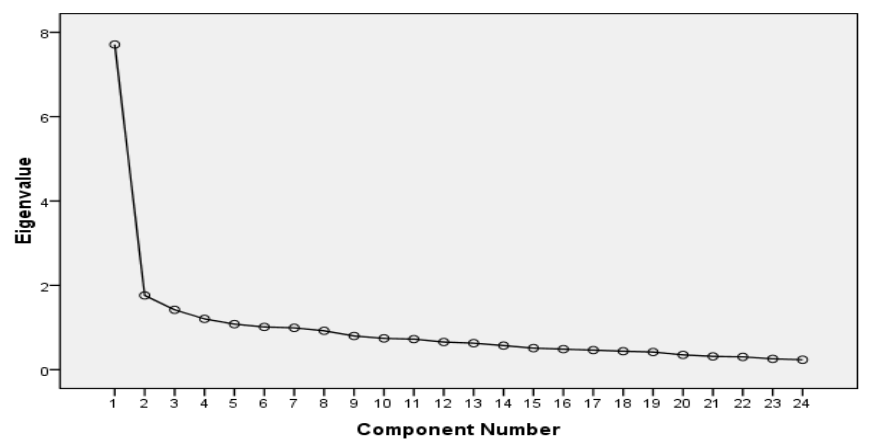

Figure 1: Gravel diagram of exploratory factor analysis of symptoms in the studied units

\section{Acknowledgements}

The present study was conducted with the code of ethics ir.Mui.reserch.Rec: 1397.371 with the financial support of Isfahan University of Medical Sciences. I would like to thank the authors of this article, the Vice Chancellor for Research of Isfahan University of Medical Sciences, and the esteemed officials of Seyed Al-Shohada and Milad Kamal hospitals.

\section{Conflict of interest}

No conflicts of interest declared.

\section{References}

1. Aune D. Plant Foods, antioxidant biomarkers, and the risk of cardiovascular disease, cancer, and mortality: A review of the evidence. Advances in Nutrition. 2019;10(4):S404-21.

2. Wilson L, Bhatnagar $\mathrm{P}$, Townsend $\mathrm{N}$. Comparing trends in mortality from cardiovascular disease and cancer in the United Kingdom, 1983-2013: joinpoint regression analysis. Population health metrics. 2017;15(1):23.

3. Ferlay J, Colombet M, Soerjomataram I, et al. Estimating the global cancer incidence and mortality in 2018: GLOBOCAN sources and methods. International journal of cancer. 2019;144(8):1941-53.

4. Farhood B, Raei B, Malekzadeh R, Shirvani M, Najafi M, Mortezazadeh T. A review of incidence and mortality of colorectal, lung, liver, thyroid, and bladder cancers in Iran and compared to other countries. Contemporary Oncology. 2019; 23(1): 7.

5. Christou N, Perraud A, Blondy S, Jauberteau MO, Battu S, Mathonnet M. E-cadherin: A potential biomarker of colorectal cancer prognosis. Oncology letters. 2017;13(6): 4571-6.

6. Enayatrad $M$, Etemad $\mathrm{K}$, Khodakarim S, Yavari P. Investigating the relationship between the incidence of colorectal cancer and human development index in Iran: An ecological study. Iran J Epidemiol. 2017; 13 (3): 244- 52. [In Persian]

7. Maughan TS, James RD, Kerr DJ, Ledermann JA, McArdle C, Seymour MT, Cohen D, Hopwood P, Johnston C, Stephens RJ. Comparison of survival, palliation, and quality of life with three chemotherapy regimens in metastatic colorectal cancer: a multicentre randomised trial. The Lancet. 2002; 359(9317): 1555-63.

8. Bahrami M, Assarroudi M, Mahmoodzadeh M. Investigation of Symptoms'Frequency, Severity, and Distress in Patients with Leukemia Admitted to Hematology-Oncology Wards of Selected Hospitals in Isfahan, Iran, in 2016. J Health System Res. 2017; 13(2): 140- 45. [In Persian] 9. Van de Poll-Franse LV, Haak HR, Coebergh JW, Janssen-Heijnen ML, Lemmens VE. Diseasespecific mortality among stage I-III colorectal cancer patients with diabetes: a large populationbased analysis. Diabetologia. 2012 Aug 1;55(8):2163-72.

10. Pashaeypoor S, Sayadi L, Khosroparviz K. Primary Immunodeficiency Diseases. 2017.

11. Prager GW, Braga S, Bystricky B, et al. Global cancer control: responding to the growing burden, rising costs and inequalities in access. ESMO Open. 2018; 3(2).

12. Portenoy RK, Thaler HT, Kornblith AB, et al. The Memorial Symptom Assessment Scale: an 
instrument for the evaluation of symptom prevalence, characteristics and distress. European J Cancer. 1994; 30(9): 1326- 36.

13. Naseri N, Taleghani F. Depression in cancer patients: the role of demographic variables. Iran $\mathbf{J}$ Cancer Nurs. 2019; 1(1): 55- 61. [In Persian]

14. Naseri N, Taleghani F. Social support and depression in Iranian cancer patients: the role of demographic variables. J caring sci. 2018; 7(3): 143- 47.

15. Hann DM, Oxman TE, Ahles TA, Furstenberg CT, Stuke TA. Social support adequacy and depression in older patients with metastatic cancer. Psycho-Oncology. 1995; 4(3): 213- 21.

16. Tan M, Karabulutlu E. Social support and hopelessness in Turkish patients with cancer. Cancer nurs. 2005; 28(3): 236- 40.

17. Rodin G, Walsh A, Zimmermann C, et al. The contribution of attachment security and social support to depressive symptoms in patients with metastatic cancer. Psycho-Oncology: Journal of the Psychological, Social and Behavioral Dimensions of Cancer. 2007; 16(12): 1080- 91.
18. Salehi Sh, Tajvidi M, Ghasemi V, Raee Z. Investigating The effect of nurses' supportive and educational care on quality of life of breast cancer patients referred for radiotherapy in Seyed AlShohada Hospital in Isfahan 2013. J Clin Nurs Midwifery. 2016; 5(2): 9- 18. [In Persian]

19. Fafouti M, Paparrigopoulos T, Zervas Y, et al. Depression, anxiety and general psychopathology in breast cancer patients: a cross-sectional control study. In Vivo. 2010; 24(5): 803- 10.

20. Pedram M, Mohammadi M, Naziri GH, Aeinparast N. Effectiveness of cognitivebehavioral group therapy on the treatment of anxiety and depression disorders and on raising hope in women with breast cancer. J Woman and Society. 2011; 1(4): 61- 75. [In Persian]. 